\title{
Simulasi Pendistribusian Spare Part Oxygen Crew Pesawat Airbus Milik Maskapai X Di Bandara Pattimura Ambon
}

\author{
Israq Mifan Junaidi ${ }^{[1]}$., Mufti Arifin ${ }^{[2]^{*}}$, Endah Yuniarti ${ }^{[3]}$ \\ [1][2][3]Prodi Teknik Penerbangan, Fakultas Teknologi Kedirgantaraan, Universitas \\ Dirgantara Marsekal Suryadarma, Jl. Halim Perdanakusuma, RT.1/RW.9, Halim \\ Perdana Kusuma, Kec. Makasar, Kota Jakarta Timur, Daerah Khusus Ibukota Jakarta \\ 13610, Indonesia. \\ *Corresponding Author : muftiarifin@gmail.com
}

\begin{abstract}
Based on field observations, there were indications of an oxygen crew leak when the plane was flying from Soekarno Hatta Airport to Ambon Pattimura Airport. In accordance with the FCOM (Flight Crew Operating Manual) for airbus aircraft, if there are 2 crew in the cockpit, the minimum emergency oxygen pressure for the flight crew is 540 $\mathrm{PSI}$. In this connection, it is necessary to analyze the effect of the distribution of spare parts oxygen crew of Airbus aircraft belonging to $X$ airline at Patimura Airport, with the aim of seeing the distribution of components at each station which are interconnected, see the influence of the expression of the spare part oxygen crew for the aircraft that will work, and see the location of storage and spare part needs. This study uses an operations research method consisting of the VAM (Vogel Approximation Method) method, the inspection method (Least Cost) and the NWC (North West Corner) method. After calculating using these 3 methods, the appropriate method for the distribution of oxygen crew spare parts is obtained, namely the VAM (Vogel Approximation Method) method at a cost of US\$141 to meet all station needs.
\end{abstract}

Keywords: Spare part, Oxygen Crew, Airbus, Pattimura Airport, NWC, Least Cost. VAM, Workshop, Station 


\section{Pendahuluan}

Salah satu komponen yang sangat berpengaruh terhadap keputusan penerbang untuk menerbangkan pesawat adalah oxygen crew. Oxygen crew adalah oksigen darurat yang digunakan oleh cre (pilot \& co-pilot) jika udara dalam kabin mengalami penurunan, atau terjadinya kebakaran di dalam kabin yang menyebabkan kekurangannya oksigen dalam ruang cockpit.

Berdasarkan observasi lapangan, ditemukan adanya indikasi kebocoran oxygen crew pada saat pesawat mulai terbang dari bandara Soekarno Hatta menuju Bandara Pattimura Ambon. Sesuai dengan FCOM (Flight Crew Operating Manual) untuk pesawat airbus jika ada 2 crew dalam cockpit maka minimum tekanan oksigen darurat untuk flight crew adalah $540^{\circ} \mathrm{PSI}$, kenyataanya oksigen hanya memiliki $340^{\circ} \mathrm{PSI}$. Sesuai dengan peraturan penerbangan, setiap pesawat harus memiliki oksigen yang berisi $540^{\circ} \mathrm{PSI}$, jika dalam cockpit hanya ada pilot \& co-pilot. Saat ingin dilakukan pergantian komponen dan komponen untuk pergantian tidak tersedia, akibatnya pesawat harus delay sampai menunggu komponen tersebut datang.

Sehubungan dengan itu, maka diperlukan simulasi pendistribusian spare part oxygen crew pesawat airbus milik maskapai $X$ di Bandara Pattimura, dengan tujuan untuk mengetahui seberapa penting cadangan spare part oxygen crew untuk pesawat airbus yang ada di Bandara Pattimura Ambon.

\section{Landasan Teori}

\subsection{Transportasi Udara}

Saat ini mayoritas masyarakat sangat membutuhkan transportasi umum, khususnya pesawat udara, selain lebih efisien untuk menempuh jarak jauh, pesawat udara juga memberikan rasa nyaman \& aman bagi masyarakat yang akan bepergian. Untuk tetap mengoptimalkan pengoperasian pesawat udara, harus dilakukan perawatan pada pesawat udara tersebut, perawatan ini harus dilakukan karena setiap komponen mempunyai batas usia tertentu sehingga komponen tersebut harus diganti. Selain itu, komponen juga harus diperbaiki bila ditemukan telah mengalami kerusakan. Secara garis besar ada dua jenis tipe perawatan pada pesawat udara, yaitu perawatan preventif dan korektif. Perawatan preventif adalah perawatan yang mencegah terjadinya kegagalan komponen sebelum komponen tersebut rusak. Sedangkan perawatan korektif adalah perawatan yang memperbaiki komponen yang rusak agar kembali ke kondisi awal. Salah satu cara untuk membantu proses perawatan berjalan sesuai dengan perencanaan adalah ketersediaan komponen cadangan, karena setiap komponen mempunyai limitasi yang harus diperhatikan untuk menjaga pesawat selalu dalam kondisi ready to flight, untuk itu pendistribusian komponen juga harus diperhatikan.

Saat penulis melakukan observasi terhadap pesawat Airbus A320 di Bandara Pattimura Ambon milik maskapai X, ditemukan indikasi kebocoran pada oxygen crew. Sesuai dengan FCOM (Flight Crew Operating Manual), limitasi oxygen crew pada pesawat Airbus A320 adalah 540 PSI, aktualnya oksigen hanya berisi $340 \mathrm{PSI}$.

\subsection{Metode Transportasi sebagai Metode Perhitungan}

Dalam penulisan skripsi penulis menggunakan metode transportasi untuk menganalisa kebutuhan sparepart komponen pada Bandara Pattimura Ambon. Metode transportasi adalah 
suatu metode yang digunakan untuk mengatur distribusi dari sumber-sumber yang menyediakan produk yang sama, ke tempat-tempat yang membutuhkan secara optimal. Metode transportasi juga digunakan untuk memecahkan masalah bisnis, pembelanjaan modal, alokasi dana untuk investasi.

\subsection{Jenis-Jenis Metode Transportasi}

Metode transportasi terdiri atas 2 langkah utama, yaitu pencarian solusi awal dan pencarian solusi optimal. Adapun beberapa metode yang digunakan untuk menentukan solusi awal, yaitu:

1. Metode NWC (North West Corner)

2. Metode Inspeksi (Least Cost)

3. Metode VAM (Vogel Approximation Method)

\subsubsection{Metode NWC (North West} Corner)

Menurut Siswanto (2006:74) Metode Sudut Barat Laut (North West Corner Method) adalah sebuah metode untuk menyusun tabel awal dengan cara mengalokasikan distribusi mulai dari sel yang terletak pada sudut kiri atas. Itulah sebabnya dinamakan metode Barat Laut.

\subsubsection{Metode Inspeksi (Least Cost)}

Menurut Render dan Heizer, Metode Least Cost adalah metode yang membuat alokasi berdasarkan kepada biaya yang terendah. Metode ini merupakan sebuah pendekatan yang sederhana.

\subsubsection{Metode VAM (Vogel}

\section{Approximation Method)}

Vogel Approximation Method (VAM) adalah salah satu metode yang sering digunakan untuk mencari biaya minimum pada persoalan transportasi.

\subsection{Metode Pengujian Solusi Optimal}

Setelah penyusunan tabel awal selesai, maka sebagai langkah selanjutnya adalah pengujian optimalitas tabel untuk mengetahui apakah biaya distribusi total telah minimum. Secara matematis, pengujian ini dilakukan untuk menjamin bahwa nilai fungsi tujuan minimum telah tercapai. Ada dua macam pengujian optimalitas algortima transportasi yaitu:.

1. Metode Stepping Stone

2. Metode MODI (Modified Distribution)

\subsubsection{Metode Stepping Stone}

Metode ini merubah alokasi produk untuk mendapatkan alokasi produksi yang optimal menggunakan cara trial and error atau cobacoba. Walaupun merubah alokasi dengan cara coba-coba, namun ada syarat yang harus diperhatikan yaitu dengan melihat pengurangan biaya per unit yang lebih besar dari pada penambahan biaya per unitnya.

\subsubsection{Metode MODI (Modified}

\section{Distribution Method)}

Metode ini dalam merubah alokasi produk untuk mendapatkan alokasi produksi yang optimal menggunakan suatu indeks perbaikan yang berdasarkan pada nilai baris dan nilai kolom. Cara untuk penentuan nilai baris dan nilai kolom menggunakan rumus: $\mathrm{Ri}$ $+\mathrm{Kj}=\mathrm{Cij}$,

Keterangan:

$\mathrm{Ri}=$ nilai baris ke $\mathrm{i}$

$\mathrm{Kj}=$ nilai baris $\mathrm{ke} \mathrm{j}$

$\mathrm{Cij}=$ biaya pengangkutan 1 unit barang dari sumber i ke tujuan 


\section{Metode Penelitian}

\subsection{Flowchart Penelitian}

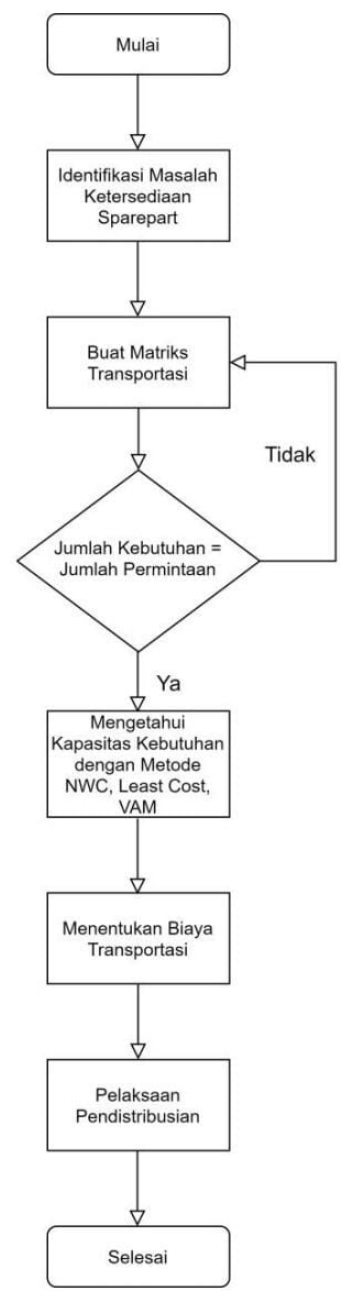

Langkah pertama setelah memulai penelitian ini adalah mengidentifikasi masalah untuk membuat matriks transportasi yang menghasilkan jumlah kebutuhan sama dengan jumlah permintaan, setelah itu menghitung kapasitas produksi dengan metode NWC, least cost, dan VAM. Setelah itu dilakukan perhitungan biaya transportasi untuk melakukan pendistribusian, kemudian penelitian selesai.

\subsection{Data Penelitian}

Tempat penelitian dilakukan di Bandara Pattimura Ambon. Maskapai X dengan Airbus A320 sebagai bahan penelitian

\section{Spesifikasi Pesawat Airbus A320}

Dalam penulisan skripsi ini penulis menggunakan pesawat Airbus A320 sebagai bahan penelitian. Spesifikasi pesawat Airbus A320 adalah pesawat penumpang komersial pertama jarak dekat sampai menengah dengan sistem kendali fly-by-wire digital, yaitu pilot mengendalikan pesawat melalui sinyal elektronik dan bukan secara mekanik.

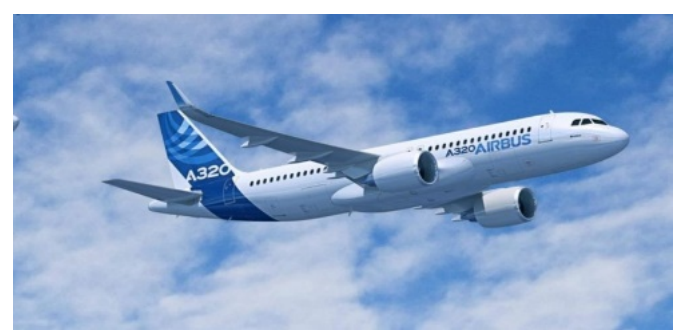

Gambar 3.2 Airbus A320 [6]

Pada 31 Januari 2011, total 4552 unit pesawat Airbus A320 family telah dikirim, di mana 4467 masih aktif dalam penerbangan. Sebagai tambahan, masih terdapat 2404 pesawat yang masih dalam pesanan

Dibandingkan dengan pesawat penumpang komersial lainnya yang meiliki kelas sama, A320 memiliki kabin satu lantai yang lebih lebar dengan diameter luar 155,5 inci $(3,95 \mathrm{~m})$, dibandingkan dengan 148 inci $(3,8 \mathrm{~m})$ pada Boeing 737 dan 131,6 inci (3,34 m) pada Boeing 717 , dan memiliki ruang bagasi atas yang lebih besar, bersama dengan teknologi fly-by-wire. Sebagai tambahan, pesawat ini memiliki sebuah ruang kargo yang dilengkapi dengan pintu besar untuk membantu proses bongkar muat kargo yang cukup besar. 
A320 memiliki sebuah ECAM (Electronic Centralised Aircraft Monitor) yang memberikan informasi kepada awak pesawat mengenai semua sistem di dalam pesawat. Dengan pengecualian versi paling awal dari $\mathrm{A} 320$.

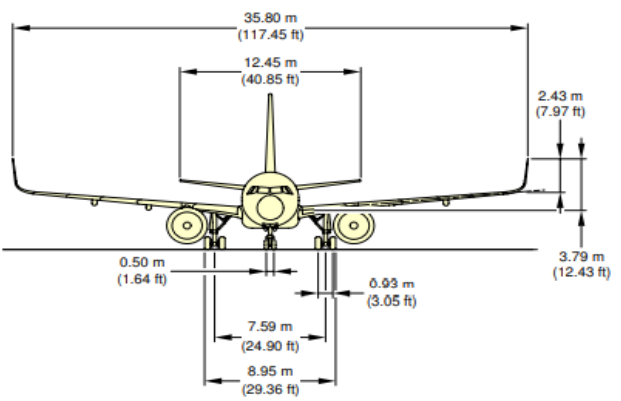

Gambar 3.3 Airbus A320 tampak dari depan ${ }^{[7]}$

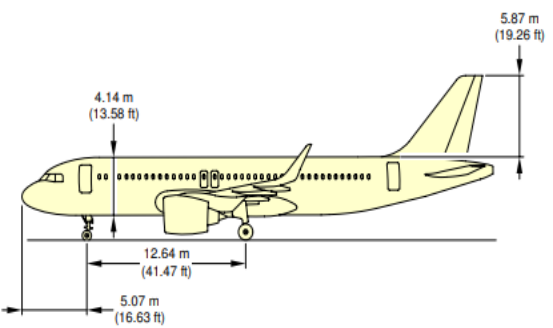

Gambar 3.4 Airbus A320 tampak dari samping ${ }^{[7]}$

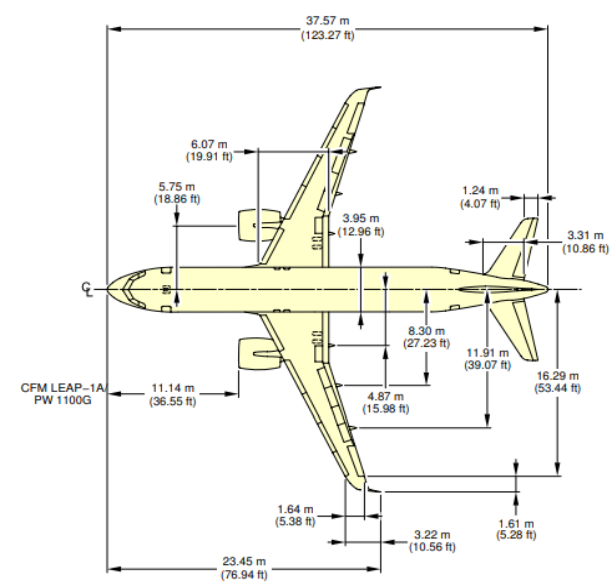

Gambar 3.5 Airbus A320 tampak dari atas ${ }^{[7]}$

\section{IV.Hasil Dan Pembahasan}

\subsection{Data Penerbangan pada Maskapai $X$}

Pesawat yang digunakan oleh maskapai $X$ untuk terbang dari Jakarta menuju Ambon hanya menggunakan jenis pesawat Airbus A320, dan di Bandara Pattimura Ambon tidak ada pesawat dari maskapai $X$ dengan status RON (Remain Over Night).

\subsection{Jumlah Kebutuhan Spare Part}

Ketersediaan spare part sangat mempengaruhi jadwal keberangkatan suatu pesawat. Jika spare part tidak tersedia saat pesawat mengalami kerusakan component, maka akan sangat berpengaruh terhadap jadwal keberangkatan, karna menunggu spare part yang dikirimkan dari station lain. Pada bulan Agustus tahun 2020, ditemukan kebocoran oxygen crew pada penerbangan tujuan Bandara Pattimura Ambon dari Bandara Soekarno Hatta, oxygen crew yang ada hanya $340 \mathrm{PSI}$, sesuai dengan FCOM limitasi yang diizinkan adalah 540 Psi. Oleh karena itu diperlukan penggantian oxygen crew yang menyebabkan penerbangan ditunda pada saat itu. Penundaan penerbangan disebabkan juga karena menunggu spare part dari station terdekat yang akan dikirim menggunakan pesawat selanjutnya. Setiap station terdekat harusnya menyediakan spare part cadangan, untuk mengantisipasi jika spare part cadangan di station utama juga tidak sesuai dengan limitasi yang ditentukan. Pada kasus ini station terdekat dari Bandara Pattimura Ambon adalah Bandara Internasional Sultan Hasanuddin Ujung Pandang \& Bandara Dominique Edward Osok, kedua station tersebut mempunyai stock spare part cadangan untuk Oxygen crew, tetapi tidak ada penerbangan yang menuju Pattimura Ambon pada hari itu Oleh 
karena itu spare part dikirim dari Bandara Soekarno Hatta, Cengkareng

\subsubsection{Jumlah Kebutuhan Spare Part Oxygen crew berdasarkan Flight Hours}

Berdasarkan pengalaman mekanik maskapai $X$ yang mengerjakan pesaawat A320, pada bulan Agustus 2020 dilakukan daily check dan ditemukan kebocoran pada oxygen crew. Tindakan yang dilakukan oleh mekanik pada saat itu adalah mengganti oxygen crew yang low pressure dengan spare part yang baru, dan dilakukan pengujian kebocoran. Setelah dilakukan pengujian, oxygen crew dalam kondisi baik. Enam bulan kemudian oxygen crew pada pesawat tersebut dilakukan kembali proses removal crew oxygen bottle untuk melaksanakan hidrostatik test. Hidrostatik test adalah tes tekanan untuk menguji kekuatan dan kebocoran pada suatu bejana bertekanan atau komponen seperti tangki, pipa, tabung, boiler, tangki penyelam (SCUBA tank, Self Contained Underwater Breathing Apparatus) dan lain-lain, dengan menggunakan zat cair sebagai media untuk mentransfer tekanan. Hasil dari pengujian akan menentukan apakah oxygen crew perlu diganti atau tidak.

\subsection{Pendistribusian Spare Part Oxygen crew}

Pendistribusian adalah penyaluran dan pembagian suatu barang kepada konsumen yang bertujuan untuk melancarkan proses pekerjaan pada suatu perusahaan. Pendistribusian komponen dilakukan berdasarkan permintaan dari konsumen, dalam hal ini konsumennya adalah Maskapai $\mathrm{X}$ di Bandara Pattimura Ambon. Proses permintaan barang dimulai dengan memasukan P//N component yang akan di request, setelah itu storeman akan memastikan component yang dibutuhkan tersedia atau tidaknya, jika component tersedia maka proses selanjutnya adalah memastikan kebutuhan dari maskapai untuk proses pengiriman spare part, jika spare part tidak tersedia bagian storeman harus memberitahu operator untuk segera mencari spare part dari station lain agar pesawat bisa segera beroperasi. Pada analisa ini Bandara Pattimura Ambon membutuhkan spare part oxygen crew untuk menggantikan oxygen crew yang low pressure, berikut adalah flowchart permintaan spare part:

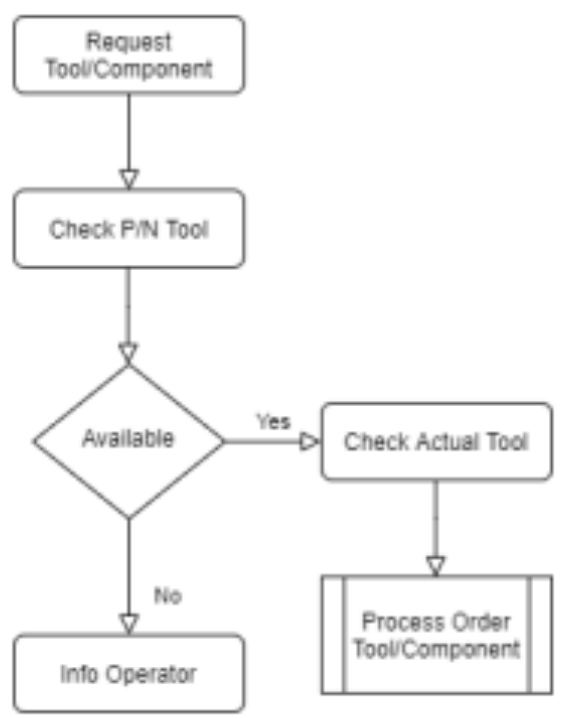

Gambar 4.1 Flowchart proses permintaan barang

\subsubsection{Request Tool/Component}

Request Tool/Component adalah permintaan barang dari station utama yang akan dikirimkan ke station terdekat melalui operator dan disampaikan ke storeman, jika station terdekat tidak mempunyai stock spare part yang dicari, maka operator akan mencarikan spare part di station lain yang mempunyai stock spare part oxygen crew.

\subsubsection{Check Part Number Tool/Component}

Sebelum melakukan proses order spare part, station yang membutuhkan spare part harus memberikan part 
number yang dibutuhkan kepada operator, agar operator bisa mencarikan part number yang sesuai. Jika spare part tersedia maka storeman akan melanjutkan proses order spare part yang dibutuhkan. Jika spare part yang dibutuhkan tidak ada di station terdekat, ataupun di gudang penyimpanan, maka operator harus melakukan pembelian spare part melalui manufaktur/supplier spare part yang dibutuhkan

\subsubsection{Check Actual Tool/Component}

Sebelum melakukan proses order tool/component operator akan memastikan part number yang dibutuhkan oleh station sama dengan part number yang tersedia di gudang, jika sudah sesuai maka spare part akan dilanjutkan menuju proses order spare part.

\subsubsection{Proses Order Spare Part}

Tahap ini merupakan tahap akhir pada flowchart permintaan spare part oleh station kepada bagian gudang. Pada tahapan ini component yang sudah di request oleh station akan dipastikan kembali jumlah dan penerima component tersebut. Setelah part number \& jumlah kebutuhan sesuai, maka selanjutnya spare part akan dikirim ke station tujuan.

\subsection{Penggunaan Metode Transportasi untuk Distribusi Barang}

Metode perhitungan yang digunakan dalam tugas akhir ini adalah metode transportasi, metode ini membahas tentang perencanaan kebutuhan spare part, biaya pengiriman, dan juga salah satu metode yang termasuk dalam metode transportasi adalah metode stepping stone. Metode ini merubah alokasi produk untuk mendapatkan alokasi produksi yang optimal menggunakan cara trial \& error. Pada analisa ini akan dihitung jumlah stock spare part, jumlah kebutuhan spare part, dan biaya pengiriman spare part.

\subsubsection{Jumlah Stock Spare Part Oxygen crew A320}

Jumlah stock spare part pada suatu station berpengaruh pada kemungkinan terjadinya delay pada suatu pesawat.

Tabel 4.5 Jumlah kebutuhan spare part oxygen crew A320 untuk 11 station

\begin{tabular}{|c|c|}
\hline Station & Jumlah Kebutuhan Per Bulan (PCS) \\
\hline UPG & 3 \\
\hline AMQ & 1 \\
\hline SOQ & 1 \\
\hline CGK & 7 \\
\hline HLP & 6 \\
\hline BPN & 3 \\
\hline DPS & 5 \\
\hline PDG & 3 \\
\hline SUB & 5 \\
\hline MDC & 4 \\
\hline KNO & 4 \\
\hline Jumlah & 42 \\
\hline
\end{tabular}

Berikut ditampilkan simulasi stock spare part pada station Pattimura Ambon \& station Ujung Pandang dan station Dominique Edward Osok sebagai station yang terdekat dari Pattimura Ambon:

Tabel 4.3 Jumlah stock spare part oxygen crew A320

\begin{tabular}{|c|c|}
\hline Station & Stock Oxygen Crew (Pcs) \\
\hline Ambon (AMQ) & 0 \\
\hline Ujung Pandang (UPG) & 2 \\
\hline Dominique Edward Osok (SOQ) & 2 \\
\hline Jumlah & 4 \\
\hline
\end{tabular}

\subsubsection{Jumlah Kebutuhan Spare Part Oxygen crew A320}

Jumlah kebutuhan spare part oxygen crew A320 dihitung menggunakan simulasi jumlah spare part yang hanya terdapat pada station utama yaitu Pattimura Ambon, dan 2 station terdekat yaitu Ujung Pandang (UPG) dan Dominique Edward Osok (SOQ). 


\subsubsection{Kapasitas Produksi Spare Part Oxygen crew A320}

Kapasitas produksi spare part Oxygen crew A320 dihitung berdasarkan jumlah produksi spare part oxygen A320 dari setiap gudang yang menyediakan supply oxygen bagi pesawat A320. Berikut adalah Tabel kapasitas produksi spare part Oxygen crew A320:

Tabel 4.6 Kapasitas produksi spare part oxygen crew A320

\begin{tabular}{|c|c|}
\hline Workshop & $\begin{array}{c}\text { Kapasitas Produksi Per Bulan } \\
\text { (Pcs) }\end{array}$ \\
\hline A (BTH) & 14 \\
\hline B (CGK) & 12 \\
\hline C (UPG) & 16 \\
\hline Jumlah & 42 \\
\hline
\end{tabular}

\subsubsection{Penentuan biaya pengiriman}

Pada penulisan tugas akhir ini biaya pengiriman ditentukan berdasarkan jarak dari setiap workshop menuju ke setiap station.Penentuan biaya pengiriman berdasarkan simulasi dari jarak setiap workshop menuju setiap station. Pada perhitungan ini biaya pengiriman di simulasikan 1 \$ per $203 \mathrm{Km}$, contoh jarak dari workshop A ke station CGK adalah $849 \mathrm{Km}$, maka $849203=4,18$ \$. Untuk mempermudah perhitungan maka hasil perhitungan dibulatkan menjadi $4 \$$ / item. untuk biaya pengiriman dari workshop A menuju station CGK.

Tabel 4.7 Jarak dari setiap workshop menuju setiap station (Kilo meters)

\begin{tabular}{|c|c|c|c|c|c|c|c|c|c|c|c|}
\hline $\begin{array}{l}\text { Ko Station } \\
\text { Dari Workahop }\end{array}$ & upc & AND & soo & $\cos$ & HLP & BPN & ons & poc & sue & NoC & KNO \\
\hline A & 1848 & 2720 & 3052 & B49 & 873 & 1448 & rest & 478 & 1345 & 2916 & EAS \\
\hline B & 1434 & 2302 & 2796 & 10 & 30 & $125 \mathrm{~T}$ & 983 & 222 & $m$ & 2001 & 1382 \\
\hline c & 10 & 950 & 1383 & 144 & 211 & 513 & 633 & 2194 & $m 2$ & 244 & 2482 \\
\hline
\end{tabular}

\subsection{Perolehan Solusi Awal Pada} Algoritma Metode Transportasi

Pada tahapan ini yang perlu dilakukan adalah membuat atau mencari sebuah solusi awal yang feasible (program awal). Masalah yang dibahas dalam Tugas Akhir ini dapat diilustrasikan sebagai suatu model Tabel transportasi pada Tabel sebagai berikut:

Tabel 4.8 Tabel transportasi

\begin{tabular}{|c|c|c|c|c|c|c|c|c|c|c|c|c|}
\hline \begin{tabular}{|r|} 
Ke Station \\
Dari Workshopop
\end{tabular} & UPG & AMMa & 500 & CGK & Hep & BPN & OPS & POG & SUB & MoC & KNO & $\begin{array}{l}\text { Kapasitas } \\
\text { Workehop }\end{array}$ \\
\hline A & $x_{21} 20$ & $\begin{array}{lll}x_{u s} & 13 \\
\end{array}$ & $x_{21}$ & $x_{13}=4$ & $x_{y}=4$ & $x_{20}, 7$ & $x_{0}, 8$ & $x_{x a} 2$ & $x_{13}, 7$ & $x_{13} 11$ & $-x_{212} 3$ & 14 \\
\hline B & \begin{tabular}{|l|l|}
$x_{n}$ & 13 \\
\end{tabular} & \begin{tabular}{l|l}
$x_{m}$ & 12 \\
\end{tabular} & $x_{n}$ & $x_{3 \mu}$ & $x_{x} \leq 2$ & $x_{x t} 6$ & $x_{m}, 5$ & $x=5$ & $x_{y 0}, \frac{13}{3}$ & $x_{2 u}$ & $-x_{2 n}=7$ & 12 \\
\hline c & $x_{21}$ & \begin{tabular}{l|l}
$x_{32}$ & 7
\end{tabular} & $x_{13} 5$ & $x_{s 4} \stackrel{7}{7}$ & $x_{3 y} 12$ & 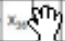 & $x_{2}, 3$ & $x_{30}=$ & $x_{3 y}-4$ & $x_{21}=3$ & $x_{24}$ & 16 \\
\hline Ketetatun Sextion & 3 & 1 & 1 & 7 & 6 & 3 & 5 & 3 & 5 & 4 & 4 & 42 \\
\hline
\end{tabular}

Masalah di atas juga dapat dirumuskan sebagai suatu model matematika sebagai berikut:

Minimum Z

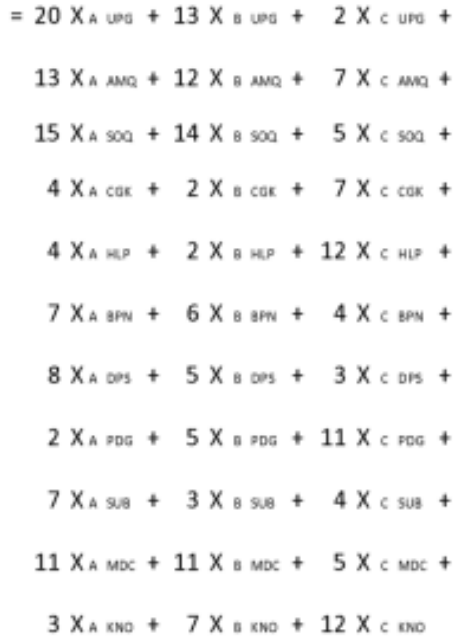

Batasan

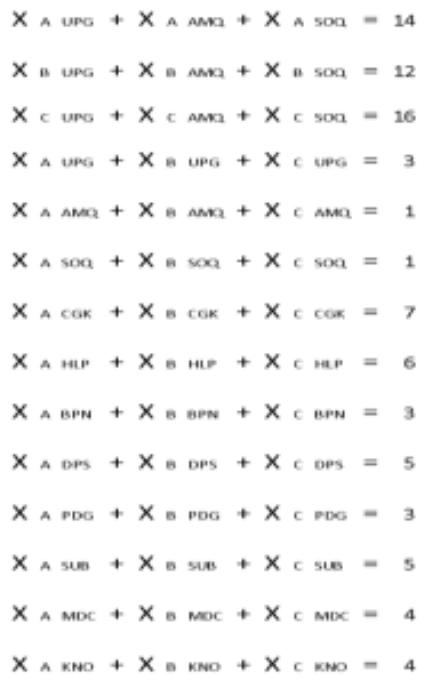




\subsubsection{Solusi Awal Aturan NWC (North West Corner)}

Langkah-langkahnya adalah sebagai berikut:

a. Mulai pada pojok kiri atas (barat laut) dan alokasikan sebanyak mungkin tanpa menyimpang dari batasan penawaran dan permintaan

b. Hilangkan baris atau kolom yang tidak dapat dialokasikan lagi, kemudian alokasikan sebanyak mungkin ke kotak di dekat baris atau kolom yang tidak dihilangkan, jika kolom atau baris sudah dihabiskan, pindahkan secara diagonal ke kotak berikutnya

c. Lanjutkan dengan cara yang sama sampai semua penawaran telah dihabiskan dan keperluan permintaan telah dipenuhi.
Tabel 4.21 Jumlah Biaya Pengangkutan metode NWC

\begin{tabular}{|c|c|c|c|}
\hline Station & Qty & Biaya (USD) & Total (USD) \\
\hline UPG & 3 & 20 & 60 \\
\hline UPG & 0 & 13 & 0 \\
\hline UPG & 0 & 2 & 0 \\
\hline$A M Q$ & 1 & 13 & 13 \\
\hline$A M Q$ & 0 & 12 & 0 \\
\hline$A M Q$ & 0 & 7 & 0 \\
\hline $\mathrm{SOQ}$ & 1 & 15 & 15 \\
\hline 500 & 0 & 14 & 0 \\
\hline $\mathrm{SOQ}$ & 0 & 5 & 0 \\
\hline CGK & 7 & 4 & 28 \\
\hline CGK & 0 & 2 & 0 \\
\hline CGK & 0 & 7 & 0 \\
\hline HLP & 2 & 4 & 8 \\
\hline HLP & 4 & 2 & 8 \\
\hline HLP & 0 & 12 & 0 \\
\hline $\mathrm{BPN}$ & 0 & 7 & 0 \\
\hline BPN & 3 & 6 & 18 \\
\hline $\mathrm{BPN}$ & 0 & 4 & 0 \\
\hline DPS & 0 & 8 & 0 \\
\hline DPS & 5 & 5 & 25 \\
\hline DPS & 0 & 3 & 0 \\
\hline PDG & 0 & 2 & 0 \\
\hline PDG & 0 & 5 & 0 \\
\hline PDG & 3 & 11 & 33 \\
\hline SUB & 0 & 7 & 0 \\
\hline SUB & 0 & 3 & 0 \\
\hline SUB & 5 & 4 & 20 \\
\hline $\mathrm{MDC}$ & 0 & 11 & 0 \\
\hline $\mathrm{MDC}$ & 0 & 11 & 0 \\
\hline $\mathrm{MDC}$ & 4 & 5 & 20 \\
\hline KNO & 0 & 3 & 0 \\
\hline KNO & 0 & 7 & 0 \\
\hline $\mathrm{KNO}$ & 4 & 12 & 48 \\
\hline \multicolumn{2}{|c|}{ Grand Total } & & 296 \\
\hline
\end{tabular}

\subsubsection{Solusi Awal Aturan Metode Inspeksi (Least Cost)}

Langkah-langkahnya adalah sebagai berikut:

a. Pilih variable Xij (kotak) dengan biaya transport (cij) terkecil dan alokasikan sebanyak mungkin. Ini akan menghabiskan baris i atau kolom j

b. Dari kotak-kotak sisanya yang layak (yaitu yang tidak terisi atau dihilangkan) pilih cij terkecil dan alokasikan sebanyakMungkin

c. Lanjutkan proses ini sampai semua penawaran dan permintaan terpenuhi. 
Tabel 4.34 Jumlah biaya pengangkutan Metode Least Cost

\begin{tabular}{|l|c|c|c|}
\hline Station & Qty & Biaya (USD) & Total (USD) \\
\hline UPG & 0 & 20 & 0 \\
\hline UPG & 0 & 13 & 0 \\
\hline UPG & 3 & 2 & 6 \\
\hline AMQ & 1 & 13 & 13 \\
\hline AMQ & 0 & 12 & 0 \\
\hline AMQ & 0 & 7 & 0 \\
\hline SOQ & 1 & 15 & 15 \\
\hline SOQ & 0 & 14 & 0 \\
\hline SOQ & 0 & 5 & 0 \\
\hline CGK & 0 & 4 & 0 \\
\hline CGK & 7 & 2 & 14 \\
\hline CGK & 0 & 7 & 0 \\
\hline HLP & 1 & 4 & 4 \\
\hline HLP & 5 & 2 & 10 \\
\hline HLP & 0 & 12 & 0 \\
\hline BPN & 0 & 7 & 0 \\
\hline BPN & 0 & 6 & 0 \\
\hline BPN & 3 & 4 & 12 \\
\hline DPS & 0 & 8 & 0 \\
\hline DPS & 0 & 5 & 0 \\
\hline DPS & 5 & 3 & 15 \\
\hline PDG & 3 & 2 & 6 \\
\hline PDG & 0 & 5 & 0 \\
\hline PDG & 0 & 11 & 0 \\
\hline SUB & 0 & 7 & 0 \\
\hline SUB & 0 & 3 & 0 \\
\hline SUB & 5 & 4 & 20 \\
\hline MDC & 4 & 11 & 44 \\
\hline MDC & 0 & 11 & 0 \\
\hline MDC & 0 & 5 & 0 \\
\hline KNO & 4 & 3 & 12 \\
\hline KNO & 0 & 7 & 0 \\
\hline KNO & 0 & 12 & 0 \\
\hline Grand Total & & 171 \\
\hline & & & \\
\hline
\end{tabular}

\subsubsection{Solusi Awal Aturan Metode VAM (Vogel Approximation Method)}

Langkah-langkahnya adalah sebagai berikut:

1. Hitung opportunity cost untuk setiap baris dan kolom. Opportunity cost untuk setiap baris ke-i dihitung dengan mengurangkan nilai cij terkecil pada baris tersebut dengan nilai cij satu tingkat lebih besar pada baris yang sama. Opportunity

2. cost kolom diperoleh dengan cara yang sama. Biaya-biaya ini adalah pinalti karena tidak memilih kotak dengan biaya minimum

3. Pilih baris atau kolom dengan opportunity cost terbesar (jika terdapat nilai kembar, pilih secara sembarang. Alokasikan sebanyak mungkin ke kotak dengan nilai cij minimum pada baris atau kolom yang dipilih

4. Hilangkan semua baris dan kolom dimana penawaran dan permintaan telah dihabiskan

5. Jika semua penawaran dan permintaan belum dipenuhi, kembali ke langkah pertama dan hitung kembali opportunity cost yang baru

Tabel 4.71 Jumlan blaya pengangkutan
\begin{tabular}{|c|c|c|c|}
\hline Station & Chy & Blaya (USD) & Total (USD) \\
\hline UPG & 0 & 20 & 0 \\
\hline UPG & 0 & 13 & 0 \\
\hline UPG & 3 & 2 & 6 \\
\hline AMQ & 0 & 13 & 0 \\
\hline AMQ & 0 & 12 & 0 \\
\hline AMQ & 1 & 7 & 7 \\
\hline SOQ & 0 & 15 & 0 \\
\hline SOQ & 0 & 14 & 0 \\
\hline SOQ & 1 & 5 & 5 \\
\hline CGK & 0 & 4 & 0 \\
\hline CGK & 7 & 2 & 14 \\
\hline CGK & 0 & 7 & 0 \\
\hline HLP & 6 & 4 & 24 \\
\hline HLP & 0 & 2 & 0 \\
\hline HLP & 0 & 12 & 0 \\
\hline BPN & 0 & 7 & 0 \\
\hline BPN & 0 & 6 & 0 \\
\hline BPN & 3 & 4 & 12 \\
\hline DPS & 1 & 8 & 8 \\
\hline DPS & 0 & 5 & 0 \\
\hline DPS & 4 & 3 & 12 \\
\hline PDG & 3 & 2 & 6 \\
\hline PDG & 0 & 5 & 0 \\
\hline PDG & 0 & 11 & 0 \\
\hline SUB & 0 & 7 & 0 \\
\hline SUB & 5 & 3 & 15 \\
\hline SUB & 0 & 4 & 0 \\
\hline MDC & 0 & 11 & 0 \\
\hline MDC & 0 & 11 & 0 \\
\hline MDC & 4 & 5 & 20 \\
\hline KNO & 4 & 3 & 12 \\
\hline KNO & 0 & 7 & 0 \\
\hline KNO & 0 & 12 & 0 \\
\hline Grand Total & & \\
\hline & & & \\
\hline
\end{tabular}

Oleh karena itu maka metode yang akan digunakan dalam perhitungan analisa skripsi ini adalah metode Vogel Approximation Method. Didapatkan urutan metode pengiriman terkecil, sebagai berikut:

1. Metode VAM (Vogel Approximation Method) dengan biaya US\$ 141 untuk memenuhi seluruh kebutuhan station 
2. Metode Least Cost dengan biaya US\$ 171 untuk memenuhi seluruh kebutuhan station

3. Metode NWC (North West Cost) dengan biaya US\$ 296 untuk memenuhi seluruh kebutuhan station.

\section{V.PENUTUP}

\subsection{Kesimpulan}

Berdasarkan hasil analisis dan pembahasan data, didapatkan kesimpulan dari penulisan tugas akhir mengenai Simulasi Pendistribusian Spare Part Oxygen crew Pesawat Airbus A320 Milik Maskapai X di Bandara Patimura Ambon sebagai berikut:

1. Berdasarkan hasil penelitan, workshop yang terdekat untuk memenuhi kebutuhan spare part di Bandara Pattimura Ambon adalah workshop C, karena jarak antara workshop $\mathrm{C}$ dan station Pattimura Ambon adalah $949 \mathrm{Km}$.

2. Pengaruh stock spare part yang tidak tersedia pada suatu station, akan menyebabkan penerbangan di station tersebut mengalami keterlambatan keberangkatan (Delay) dan menyebabkan kerugian bagi masyarakat dan maskapai.

3. Kebutuhan spare part oxygen crew seharusnya tersedia dengan jumlah mininum untuk setiap station, untuk biaya

4. pengirimannya sesuai dengan beberapa metode perhitungan, maka ditentukan metode VAM (Vogel Approximation Method)

5. merupakan yang biaya pengirimannya paling kecil, yaitu US\$ 141 untuk mencukupi seluruh kebutuhan spare part disemua station.

\subsection{Saran}

Adapun saran dari hasil penelitian ini antara lain adalah:

1. Bagi Pembaca, hasil penelitian ini diharapkan dapat menambah wawasan pengetahuan tentang oxygen crew pada pesawat, dan juga pengaruh pendistribusian sparepart component terhadap kinerja pesawat terbang.

2. Bagi Maskapai X, diharapkan penulisan tugas akhir ini memberikan acuan tentang pengaruh jumlah stock spare part yang bisa menyebabkan terjadinya delay dan menyebabkan kerugian bagi maskapai X.

3. Bagi Maskapai X diharapkan penulisan tugas akhir ini memberikan acuan tentang metode transportasi yang digunakan untuk melakukan pendistribusian spare part component.

4. Perhitungan dalam tugas akhir ini menggunakan simulasi, oleh karena itu hasil dari perhitungan perlu dikembangkan lagi agar bisa mendapatkan hasil optimum bagi pendistribusian spare part component.

\section{DAFTAR PUSTAKA}

[1] Luis Comendado, ICAO International Standart Atmosphere https://flightacademy.info/icaointernational-standardatmosphere diakses pada 16 November 2020.

[2] Airbus S.AS, 2020, A320 Spesification, https://www.airbus.com/aircraft/ passenger-aircraft/a320-

family/a320neo.html diakses pada 16 November 2020. 
[3] Sprint Aviation, Crew Oxygen Overhaul Fall Special http://sprintaviation.com/crew-oxygenmask-overhaul-fall-special/ diakses pada 15 November 2020.

[4] Hope Church Nottingham, Airplane Oxygen Mask https://www.hopechurchnotting ham.org/2017lookafteryourself/a irplane-oxygen-mask/ diakses pada 15 November 2020.

[5] Aero Expo, Aircraft Oxygen System https://www.aeroexpo.online/pro d/collins-aerospace-rockwellcollins/product-17041020210.html diakses pada 15 November 2020.

[6] Runway Girl Network, AIM Altitude selected as Airbus A320 SFE galley supplier

https://runwaygirlnetwork.com/2 018/09/27/press-release-aimaltitude-selected-as-airbus-a320sfe-galley-supplier/ diakses pada 15 November 2020

[7] Airbus S.AS, 2020, A320 Spesification,

https://www.airbus.com/aircraft/ passenger-aircraft/a320family/a320neo.htmI diakses pada 16 November 2020.

[8] IGNASIUS JONAN, 2015, GENERAL OPERATING AND FLIGHT RULES http://jdih.dephub.go.id/assets/u udocs/permen/2015/PM 94 TAH UN 2015.pdf diakses pada 16 November 2020.

[9] https://www.airmilescalculator.c om diakses pada 16 November 2020

[10] https://skyvector.com diakses pada 16 November 2020

[11] Airbus, 2020, Aircraft Maintenance Manual A320 Chapter 35 Oxygen
SUBTASK

$35-00-00-00$

01/Nov/2020.

[12] Airbus, 2020, Aircraft Maintenance Manual A320 Chapter 35 Oxygen Crew SUBTASK 35-10-00-00 01/Nov/2020.

[13] Airbus, 2020, Aircraft Maintenance Manual A320 Chapter 35 Oxygen Crew SUBTASK 35-20-00-00 01/Nov/2020.

[14] Airbus, 2005, A320 Aircraft Characteristics Airport and Maintenance Planning, Airbus S.A.S : France.

[15] Tastrawati, N. 2015, Pemograman Linier : Model Transportasi, Skripsi, Fakultas Matematika dan IImu Pengetahuan Alam, Universitas Udayana, Bali. 